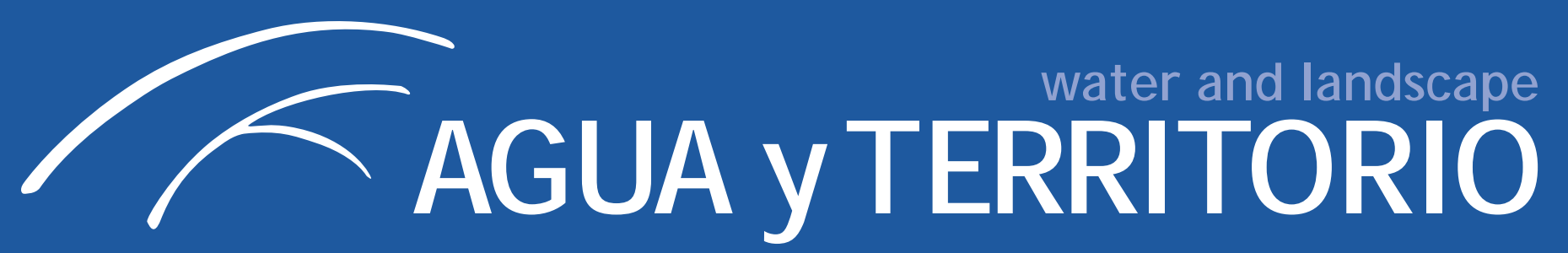

\title{
III Encuentro de Políticas Públicas de Termalismo
}

\author{
Organiza: Observatorio Nacional del Termalismo y Desarrollo Rural y Termatalia \\ Lugar de celebración: Autódromo Internacional de Termas de Río Hondo
}

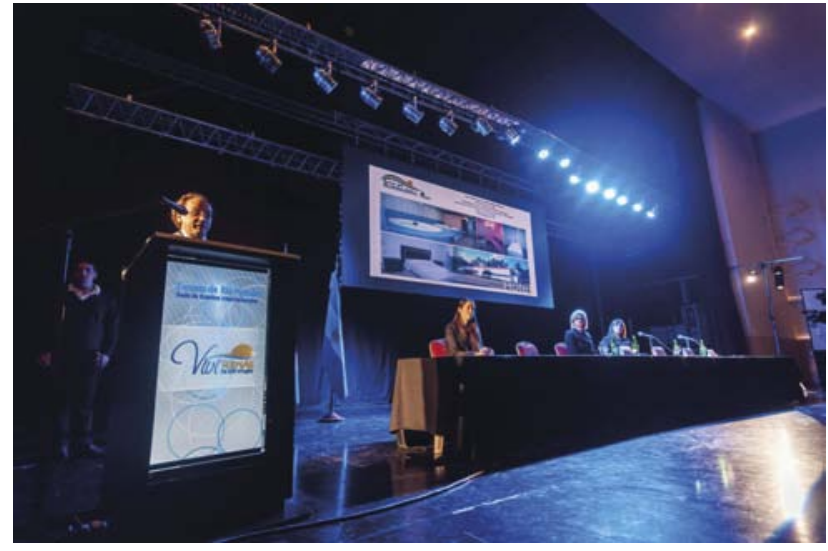

En el marco de la 14ạ edición de TERMATALIA, Feria Internacional de Turismo de Salud y Bienestar, desarrollada en la mayor Ciudad Termal de Latinoamérica, Termas del Río Hondo (Santiago del Estero, Argentina), se ha celebrado el III Encuentro de Políticas Públicas de Termalismo, organizado por la Feria Termatalia, Expourense y el Observatorio del Termalismo. Tanto la Feria como el Encuentro han contado con la gran acogida y las facilidades ofrecidas por la ciudad de Termas de Río Hondo, por la provincia de Santiago del Estero y por el Gobierno de la Nación de Argentina, así como por los organizadores y patrocinadores de dicha Feria.

En el transcurso de la reunión se han analizado las potencialidades de desarrollo del sector y las experiencias de planificación y gestión pública del Termalismo en diversos países, así como las problemáticas que amenazan 0 impiden el adecuado desarrollo del sector. De las intervenciones y debates planteados en ella debemos destacar las siguientes RECOMENDACIONES dirigidas tanto a los gobiernos nacionales, regionales y locales, como al conj unto de agentes del sector.

1. Promover el reconocimiento del Termalismo y el Turismo de Salud como un sector con elevadas potencialidades para contribuir de forma sostenible al desarrollo rural
Termas de Río Hondo, Argentina, 2 de octubre de 2014

y territorial, como motor de diversificación económica, generación de empleo, desarrollo turístico y cohesión social.

2. Plantear en los diferentes niveles de la Administración la elaboración de normativas que fomenten el desarroIlo integral del sector termal desde el ámbito territorial, turístico y sanitario, que garanticen al mismo tiempo la protección y aprovechamiento sostenible de los recursos termales, como se ha hecho en los últimos años en países como Italia y Portugal.

3. Desarrollar el Termalismo desde la perspectiva de su contribución a la prevención y mejora de la salud de las personas, como vienen demostrando numerosas investigaciones científicas sobre aguas minerales y mineromedicinales y sobre sus beneficios asistenciales, desarrolladas en todo el mundo bajo la perspectiva que también recomienda la Organización Mundial para la Salud.

4. Promover desde las diferentes administraciones públicas programas de Termalismo Social para los mayores y otros colectivos sociales, teniendo en cuenta expe-

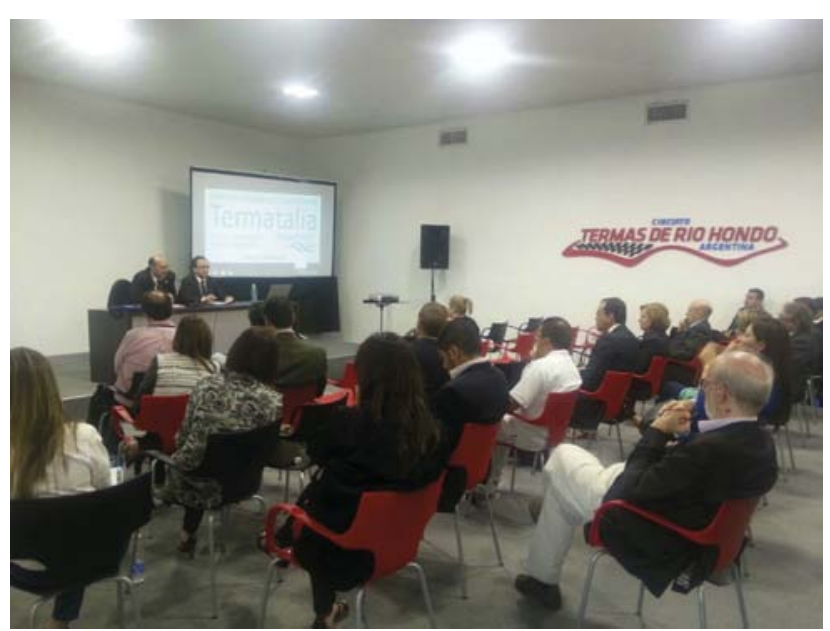




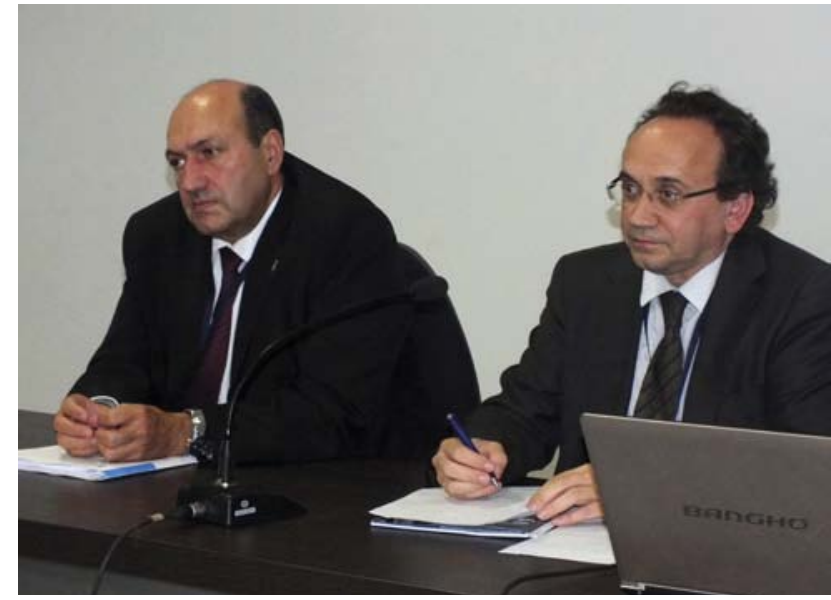

riencias como las que se desarrollan desde hace 25 años en España a través del IMSERSO, y más recientemente desde diversas Comunidades Autónomas y Diputaciones Provinciales españolas.

5. Garantizar una protección reforzada de los acuíferos termales a través de la legislación, la planificación y la gestión pública, impidiendo el desarrollo de actividades que puedan provocar la contaminación de las zonas de recarga y a lo largo de todo el circuito hidrológico, hasta su aprovechamiento en instalaciones termales y en las mismas, garantizando la seguridad y la salud de las personas.
6. Facilitar desde las administraciones públicas los apoyos técnicos y financieros para crear o mejorar, según el caso, la oferta termal, sus instalaciones terapéuticas, turísticas o lúdicas, así como la oferta complementaria de los destinos o villas termales, como inversiones productivas sostenibles con un gran impacto para el desarrollo rural y territorial.

7. Invitar a los gobiernos locales que cuentan con recursos termales a trabajar en común y a desarrollar una acción planificada y activa para convertir a sus municipios en auténticos destinos 0 villas termales saludables, protegiendo sus recursos y favoreciendo el desarrollo de inversiones productivas para su explotación.

8. Asegurar la sensibilización de las comunidades locales para que se impliquen en la gobernanza de los recursos termales de sus respectivos territorios como estrategia para garantizar su protección y aprovechamiento social.

9. Desarrollar acciones de investigación y de capacitación de profesionales en el sector del Termalismo, el Turismo de Salud y la Hidrología Médica.

10. Celebrar en los municipios termales, con motivo del Día Mundial del Agua, acciones de sensibilización, educación ambiental y puesta en valor de las aguas termales como recurso natural que contribuye a la salud y al bienestar humanos. 